\title{
JUAN CHACÓN, UN PINTOR CASI DESCONOCIDO EN LA SEVILLA DEL XVI: UN RECORRIDO POR SU VIDA Y OBRA
}

\author{
JUAN CHACÓN, AN ALMOST UNKNOWN $16^{\mathrm{TH}}$ \\ CENTURY PAINTER IN SEVILLE: A JOURNEY THROUGH \\ HIS LIFE AND WORK
}

\author{
Elena EsCuredo BARRAdo \\ Universidad de Sevilla. España \\ ORCID: 0000-0001-7976-8925 \\ escuredo@us.es
}

\begin{abstract}
La demanda artística en la Sevilla del siglo XVI fue copiosa debido a la prosperidad de una ciudad favorecida por el comercio americano. Uno de los artistas que disfrutaron de este momento de esplendor y se beneficiaron de los múltiples encargos que se requerían tanto desde el cabildo catedralicio como de instituciones conventuales o el patrocinio privado fue Juan Chacón, un pintor afamado y reconocido por sus contemporáneos, pero recluido en el olvido por no haber trascendido apenas nada de su extensa y prolija producción. No obstante, los hallazgos documentales permiten conocer diferentes aspectos de su vida y obra, intentando así devolverle el éxito que el tiempo le negó.

Palabras clave: Juan Chacón; pintor; siglo XVI; Sevilla; catedral.
\end{abstract}

The artistic demand during the $16^{\text {th }}$ century in Seville was plentiful, due to the success of a city favored by the oceanic trade. Juan Chacón was one of the artists who lived this great history moment and benefited himself from the numerous artistic orders which were required by the cathedral, the monastic institutions and private initiative. He was a famous and recognized painter, but he has been forgotten because their large and prolix work has not been conserved. However, the discovery of some documents in the archive of historical manuscripts allow to know different aspects of their life and job, in order to give him back the success snatched by the passing of time.

Keywords: Juan Chacón; painter; $16^{\text {th }}$ century; Seville; cathedral.

Resulta inocente pensar que en la Sevilla del quinientos solo triunfaron artistas como Alejo Fernández, Pedro de Campaña, Hernando de Esturmio, Luis de Vargas, Villegas Marmolejo, Vasco Pereira o Alonso Vázquez. La efervescencia de una ciudad al alza y la demanda de productos artísticos permitieron tejer una estructura gremial compleja, integrada por numerosos individuos locales y 
foráneos trabajando al servicio de la demanda cercana o aquella que llegaba de ultramar.

Los pintores de imaginería se mezclaban con doradores o con aquellos especializados en la pintura de sargas, y los encargos se sucedían tanto por parte de particulares como de órdenes religiosas y, sobre todo, del cabildo de la catedral, el cual estaba a la vanguardia de la promoción artística del momento. En el tercio central del siglo XVI, los encargos pictóricos de la Magna Hispalense iban a parar en gran medida al artista Antón Pérez, a quien se le podría considerar "pintor de la Santa Yglesia de Sevilla"1. Junto a él, en las nóminas y adventicios del archivo de la catedral, aparece el nombre de un pintor hasta hoy casi desconocido: Juan Chacón, un artista cuya trayectoria profesional abarca buena parte del siglo XVI.

A la espera del hallazgo de nuevos testimonios documentales, se desconoce su lugar de nacimiento, así como el maestro pintor con el que pudo adquirir los rudimentos técnicos del oficio. No obstante, lo cierto es que ya en enero de 1548 tomó por aprendiz a un tal Felipe, de nueve años de edad ${ }^{2}$. Esta es la primera referencia documental que se tiene del artista, y de la que se deduce que tenía que tener más de 25 años y haber superado el examen de maestro pintor, por lo que su fecha de nacimiento podría fijarse en los primeros años de la década de los veinte.

Durante los años centrales del siglo, el pintor estuvo avecindado en distintas collaciones. En 1550 vivía en la del Salvador ${ }^{3}$. No obstante, en 1551, habitaba en la zona próxima a la iglesia de San Marcos, pues es entonces cuando arrienda al monedero Juan Morante las casas en las que moraba, por tiempo de un año y por precio de 9.000 maravedíes $^{4}$. En abril de ese mismo año, se puede documentar en Omnium Sanctorum, junto a su primera mujer Elvira Rodríguez, gracias a un poder por el que el pintor otorga licencia a su esposa para vender unas casas por 7.000 maravedíes y 14 reales de pago y censo perpetuo ${ }^{5}$. Aunque pudiera parecer baladí, la información contenida en todos estos documentos permite conocer su situación socioeconómica. Debió tener cierta solvencia, dada la posesión de diversos inmuebles en varias collaciones, lo cual le permitió cambiar con asiduidad de morada, así como obtener, en caso de alquilarlas, un ingreso extra.

La primera noticia relativa a su actividad artística data de 1553, siendo paradójicamente esta su única obra conservada, gracias a la cual se puede estudiar su estilo, aunque de forma muy sucinta. Fue entonces cuando se obliga a pintar

${ }^{1}$ Su figura fue bien estudiada por SERRERA, Juan Miguel: "Antón Pérez, un pintor del siglo XVI", Archivo Hispalense, 185, 1977, pp. 127-148.

2 SANCHO CORBACHO, Heliodoro: "Arte sevillano de los siglos XVI y XVII", en Documentos para la Historia del Arte en Andalucía. T. III. Sevilla, 1931, p. 16.

${ }^{3}$ Ibidem.

${ }^{4}$ AHPSPN (Archivo Histórico de la Provincia de Sevilla, Protocolos Notariales), leg. 17511, ff. 663-ss.

5 AHPSPN, leg. 17512, ff. 2030-ss.

LABORATORIO DE ARTE 31 (2019), pp. 143-160, ISSN 1130-5762

e-ISSN 2253-8305 - DOI http://dx.doi.org/10.12795/LA.2019.i31.09 
un retablo junto a Villegas Marmolejo para la iglesia del hospital de San Lázaro, extramuros de la ciudad de Sevilla, por encargo del mayoral Antonio Bélez de Alcocer. Se trata de una obra que en la actualidad presenta una composición y ordenación distinta a la concertada, pues en inicio contaba con 10 tablas de las cuales han desaparecido la Anunciación que ocupaba los extremos superiores, el Padre Eterno que remataba el conjunto y las tablas de las calles centrales, donde destacaba un San Lázaro vestido de pontifical y que fue expoliado y enviado a Madrid en $1811^{6}$. De las tablas conservadas, el estilo diferencial de La Coronación de espinas (Figura 1) y el Cristo llevando la cruz (Figura 2), del banco, llevó al profesor Serrera a vincularlas al pincel de Juan Chacón, desligándolas de las restantes de Villegas. El estado de conservación en que se encuentran en la actualidad es bastante deplorable, pues al craquelado de la capa de barniz se une una considerable oquedad en la superficie de la tabla que representa la Coronación, y que deja ver la urdimbre de la tela. El desperfecto se intentó velar disponiendo sobre él una pegatina, hoy casi inexistente.

No obstante, también se podría reconocer el arte de Chacón en la tabla superior izquierda, donde se representa la Aparición de Cristo a la Magdalena (Figura 3). Cristo aparece envuelto en una escurridiza túnica roja que deja al descubierto parte del pecho y el hombro del brazo derecho, con el que bendice a la Magdalena arrodillada a sus pies. La disposición en tres cuartos del cuerpo del Mesías obliga a disponer el hombro en escorzo, lo que supone un reto visual a la hora de tratar la anatomía. La tímida soltura con la que lo solventa y la cierta disociación de los miembros corporales en comparación a la habilidad plástica de Villegas para tratar estos problemas anatómicos en sus composiciones, lleva a pensar que quizás detrás de esta figura está el trabajo de Juan Chacón. Asimismo, la detenida observación de los rostros, el estudio formal de los rasgos y el análisis del tratamiento de las sombras en las distintas tablas, pueden respaldar la atribución propuesta.

Fue un pintor que debió aglutinar en su taller a un buen número de aprendices, pues en 1553 y 1554 se confirma la presencia de dos muchachos, con los que firma sendos contratos de aprendizaje ${ }^{7}$. Además de adquirir ventaja profesional de ellos, tener aprendices a su cargo suponía un gasto adicional, pues no se debe olvidar que, al tiempo que les enseñaba el oficio, debía encargarse de su manutención, dándoles techo, comida y ropa, lo que requería del maestro un nivel

${ }^{6}$ SERRERA, Juan Miguel: Pedro de Villegas Marmolejo. Sevilla, 1976, p. 68.

7 En 1553, firma un contrato de aprendizaje de tres años con un tal Gonzalo de Herrera, vecino de la villa de Mansilla. AHPSPN, leg. 17520, ff. 1232-ss. En 1554, Evaldino, a quien tutorizaba su cuñado, de un vecino de Jerez de la Frontera. En mismo año, también aparece junto a su mujer reconociendo un señorío a Antón de la Coba, notario mayor. AHPSPN, leg. 17523, registro 70, s. f. 
económico importante para poder hacer frente a los gastos ${ }^{8}$. Estos acuerdos resultan igualmente relevantes en la medida que lo presentan como pintor de sargas. La cualificación para Juan Chacón según los documentos notariales es variada, ya que en ocasiones se le presenta como simple "pintor", y en otras como "pintor de ymaginería" o "pintor de sargas". Aunque los trabajos en sarga requieren de una menor pericia, fueron muy valorados y demandados en la Sevilla del momento, pues servían para conmemorar diversos acontecimientos, tanto en moradas privadas como en lugares públicos, siendo concebidas como obras que pudieran transportarse o almacenarse con cierta facilidad. Estas razones exigían la utilización de un soporte ligero y flexible como el lienzo; por ello, las fibras empleadas eran de lino y quizás, en ocasiones, de cáñamo. En Sevilla fue común el hecho de que la pintura de sargas se practicara en lienzos ya usados, como bien se demuestra en las ordenanzas, algo que terminó prohibiéndose debido a que se ocultaba la condición del soporte al comprador ${ }^{9}$.

Fue el de 1554 uno de los años mejor documentados del artista, pues en junio, según recogen los libros de adventicios del archivo catedralicio, recibió un pago por motivo de cuatro tablas doradas destinadas al altar mayor, "que vienen sobre el altar de pilar a pilar", trabajo que fue remunerado en 4 ducados $^{10}$. Ese mismo mes se comprometió con Antonio del Corro, canónigo y visitador de las capillas de la Santa Iglesia Catedral, a pintar y dorar un retablo para la parroquia de Casaluenga, la cual se encontraba bajo la advocación de Santa Ana. Chacón, a quien se nombra como "pintor de ymagimeria", realizaría los trabajos pictóricos,

${ }^{8} \mathrm{Su}$ saneada economía queda también probada con la compra de una esclava de color negro y de 25 años. Fue adquirida, en 1565, por 100 ducados de oro -que montaban 37.500 maravedíes-, una cantidad nada desdeñable, puesto que el ajuar medio de una familia acomodada ascendería a los 150.000 maravedíes mientras que con 5.000 maravedíes podía alimentarse una pareja durante seis u ocho meses, en un cálculo aproximado. AHPSPN, leg. 17585, f. 276. Para saber más sobre los precios en Sevilla y la revolución que sufrieron en el siglo XVI, ver HAMILTON, Earl J.: El tesoro americano y la revolución de los precios en España, 1501-1650. Barcelona, 2000.

${ }^{9}$ Las ordenanzas son extensas con relación a los pintores de sargas, de lo que se deduce su importancia y el interés en su control y protección por medio de una serie de cláusulas que englobaban desde las condiciones para abrir una tienda hasta los requisitos para formar a un aprendiz. VARELA DE SALAMANCA, Juan (ed.): Recopilación de las Ordenanzas de la Muy Noble y Muy Leal ciudad de Sevilla. Sevilla, 1527, p. 163. Para saber más sobre esta especialización, ver SANTOS GÓMEZ, Sonia y SAN ANDRÉS MOYA, Margarita: "La pintura de sargas", Archivo Español de Arte, 305, 2004, pp. 59-74.

${ }_{10}$ ACS (Archivo de la catedral de Sevilla), sección Fábrica, serie Adventicios, lib. 263, f. $54 \mathrm{v}$. 
mientras que la talla fue encargada a Pedro Becerril, siendo todo el conjunto retablístico fiado por el pintor Blas López ${ }^{11}$.

Además de aceptar encargos para pintar sargas, tablas o dorar paneles, debió ser un reputado pintor de camas, una industria de gran auge en la ciudad ${ }^{12}$. Según un documento notarial, el pintor cordobés Francisco del Rosal, encargó a Chacón una cama de lienzo pintada de cuatro paños de figuras, por precio de 24 ducados. Debido al incumplimiento de dicho pago, fue detenido por un mensajero en Córdoba, según el poder que el pintor sevillano había dado a su criado ${ }^{13}$. A pesar de ser un documento indirecto, permite conocer una nueva faceta del artista quien, como muchos otros, incluyó este tipo de obras dentro de su repertorio. Siguiendo una tradición artesanal medieval, los pintores sevillanos del siglo XVI pintaban indistintamente camas, rejas, banderas y gallardetes; daban muestras para vidrieras, bordados y tapicerías; pintaban cajas de boticas y de órganos; decoraban los cirios pascuales; intervenían en las decoraciones efímeras sacras y profanas; esculpían, policromaban y doraban. De este modo, los testimonios escritos permiten reconocer a Chacón como un artífice activo y polisémico, capaz de atender los más variopintos encargos, sin encasillarse en una única disciplina, paradigma del artista-artesano que aún no se había sacudido los resabios medievales para abrazar la liberalidad de las artes.

En los años sucesivos atendió distintos encargos para la catedral. Así, en 1555, Chacón recibió 945 maravedíes por la pintura que efectuó en 21 cruces para los altares (45 por cada una $)^{14}$. La obra fue satisfecha la tercera semana de abril, por lo que pudieran ser cruces destinadas a la celebración de la Semana Santa. Meses más tarde, en octubre, recibió 6 reales por dorar y platear la espada del San Pablo que, junto a San Pedro, custodia la islámica Puerta del Perdón ${ }^{15}$. Por su parte, y según informa Gestoso, en el año de 1556, se le pagaron 4.875 maravedíes por la hechura de los vestidos de los seis cantorcitos y dos pastorcitos que

${ }^{11}$ Este encargo fue dado a conocer por HERNÁNDEZ DÍAZ, José: Arte y artistas del Renacimiento en Sevilla, en Documentos para la Historia del Arte en Andalucía. T VI. Sevilla, 1935 , p. 80.

12 Véase ESCUREDO, Elena y JAPÓN, Rafael: "Una cama sevillana para el barón de Petrapersia: obra de los pintores Gonzalo de Flores y Hernando de Alcalá", Laboratorio de Arte, 27, 2015, pp. 549-558.

13 AHPSPN, leg. 17523, ff. 1977-ss.

${ }^{14}$ ACS, sección Fábrica, serie Adventicios, lib. 264, f. 36.

15 ACS, sección Fábrica, serie Adventicios, lib. 264, f. 80. Esculturas realizadas por Miguel Perrín. Para conocer más acerca de este artista ver LAGUNA, Teresa: "Llegada y primeras obras de Miguel Perrin en la Catedral de Sevilla: el programa escultórico de la reconstrucción del Cimborrio de Juan Gil de Hontañón”, Laboratorio de Arte, 24, 2012, pp. 137-162. 
intervendrían en las celebraciones del día del Corpus Christi, fiesta que se erigía como la manifestación cívico-religiosa más importante del calendario litúrgico ${ }^{16}$.

La otra gran fiesta de la ciudad era la Semana Santa. El culto a la devoción en torno a la Pasión y Muerte de Cristo había aumentado progresivamente en el siglo XV, consolidándose definitivamente en la centuria siguiente. Los gastos ocasionados por ambas festividades aparecen frecuentemente mezclados en los libros de fábrica, lo que lleva a pensar que durante cierto tiempo el desarrollo y organización de estas celebraciones debieron de correr en paralelo. Desde principios de marzo se comenzaba a preparar el monumento eucarístico destinado a presidir las festividades del Jueves Santo. En el aderezo y preparación del mismo participaban diversos artistas, quienes atendían las peticiones del cabildo para que el monumento luciera con sus mejores galas. Chacón fue uno de esos pintores asiduos en las labores subalternas de pintura, actuando en solitario o como ayudante del protegido del cabildo, Antón Pérez. Junto a él, en 1557, pinta y dora la cartela de pergamino destinada a decorar el cirio pascual, por precio de 6.000 maravedíes ${ }^{17}$. Este pergamino ocuparía la parte superior del cirio, mientras que la inferior se ornamentaba con un lienzo en el que figuraba al óleo el rey San Fernando, imagen que se encargó de repintar. Poco tiempo después, ya en solitario, fue el encargado de dorar y pintar cuatro de las columnas -con sus respectivas basas y capiteles- del citado monumento, y, en el año 1561, el cabildo le pagó tres ducados por hacer dos pedestales dorados y aderezar cinco figuras que allí se encontraban ${ }^{18}$. Todos estos trabajos, en torno al cabildo catedralicio, le permitieron establecer relación con lo más granado de la pintura sevillana, siendo testigo de excepción de cómo evolucionaban los gustos, de cómo se abandonaba el dorado medieval en favor del orden romano y de cómo el renacimiento se hermanaba con el gótico, en una simbiosis perfecta, bajo los muros de un templo sin igual.

Como ocurriera con otros pintores contemporáneos, como Campaña, Zamora, Alfián, Villegas, también Chacón tuvo que acometer encargos de obras escultóricas. En 1560, tres labradores naturales de la villa de Brenes pagaron 20

${ }^{16}$ Los orígenes de esta fiesta en Europa hay que buscarlos en 1230, cuando la monja Juliana de Monte Cornilon, en Lieja, tuvo una revelación en la que Jesucristo le inspiró la celebración de una fiesta en honor del Cuerpo de Dios. En 1264, Urbano IV, mediante la bula Transiturus de hoc Mundo, refrendaba la celebración de la fiesta del Corpus. Por su parte, fue el papa Juan XXII quien mandó que se hiciera una procesión para conmemorar este día, en 1317. MONTES ROMERO-CAMACHO, Isabel: "La liturgia hispalense y su influjo en América”, en Andalucía y América en el siglo XVI. Vol. II. Sevilla, 1983, p. 11.

${ }^{17}$ La noticia fue dada por GESTOSO Y PÉREZ, José: Ensayo de un diccionario de los artifices que florecieron en Sevilla desde el siglo XIII al XVIII. T. II. Sevilla, 1900, p. 27; y recogida también por SERRERA, Juan Miguel: "Pinturas y pintores del siglo XVI en la Catedral de Sevilla", en La Catedral de Sevilla. Sevilla, 1984, p. 358.

18 ACS, sección Fábrica, serie Adventicios, lib. 266, f. 24; y ACS, sección Fábrica, serie Adventicios, lib. 270, f. 34v. 
ducados por "un Christo de molduras ansi por la hechura de otros adereços que tiene con su cruz en que estaba puesto"19. El documento es parco en detalles, pues no hace referencia al destino del encargo, pudiéndose tratar de una obra de altar o bien, de una imagen procesional, quizás para la cofradía de su gremio. Hoy en día nada queda de este Crucificado, que se perdió en las grietas del tiempo sin que ningún otro testimonio pueda corroborar su existencia. Su habilidad en el arte de esculpir ya se podía entrever en los encargos que recibía de parte del cabildo, puesto que su actuación en ciertos trabajos de aderezo del monumento le obligaba a ser diestro con el cincel. Sin embargo, este es el primer y único contrato que se conoce para una obra figurativa y de cierta envergadura, lo que lleva a pensar que, a pesar de la existencia de ordenanzas, el límite entre las artes en la Sevilla del siglo XVI era una fina línea que se desdibujaba con facilidad y al antojo tanto de los comitentes como de los artistas. Un año más tarde, sus dotes escultóricas serían de nuevo requeridas por la catedral sevillana, pues en los pagos se recoge el cobro de 6 ducados a cuenta de cinco figuras que hizo para el monumento ${ }^{20}$. No se especifica cuál era su iconografía, quizás algún santo, figura secundaria o serafín de menor entidad, pero el hecho de ir destinadas a adornar la mole lignaria pascual permite pensar en Chacón como un escultor muy competente y profesional en el acabado de sus trabajos, aunque no tuviera la entidad de Juan Bautista Vázquez el Viejo o Juan Giralte. El último de los encargos relacionados con el monumento fue acometido en abril de 1564, recibiendo tres reales por aderezar la figura de la $F e$, cuya silueta coronaba la cúspide ${ }^{21}$. Todos estos trabajos demuestran la constante preocupación de la catedral por tener a punto y en óptimas condiciones un monumento llamado a glorificar a Dios en su semana grande.

A todo lo dicho se le une un cargo, cuanto menos, sorprendente. Una de las noticias más curiosas de su vida es aquella que lo presenta al frente de la mayordomía del monasterio y convento de religiosas de Santa Clara. Fue en 1566 cuando la abadesa, tras acuerdo con las demás hermanas, elegían al pintor para esta función. Prometió, en presencia de su mujer Elvira Rodríguez, que se mantendría al frente del cargo ejecutándolo convenientemente, como "un fiel e buen mayordomo debe" ${ }^{22}$. De este modo, Juan Chacón se convertía en una persona de confianza para las monjas, adoptando las funciones propias del cargo. Era su

${ }^{19} \mathrm{El}$ documento notarial corresponde al último pago de la obra (10 ducados), estando ya esta en manos de sus promotores. AHPSPN, leg. 17551, registro 3, f. 58-ss.

20 ACS, sección Fábrica, serie Adventicios, lib. 270, f. 34v.

${ }^{21}$ ACS, sección Fábrica, serie Adventicios, lib. 273, f. 37v. Su última relación con el cabildo data de 1574, cuando se le libraron 6.358 maravedíes por la pintura de los medios carros que hizo para la comunidad italiana, los cuales participarían en la festividad del Corpus Christi. GESTOSO Y PÉREZ, José: Ensayo..., op. cit., p. 27.

${ }^{22}$ Fueron fiadores de esta escritura Francisco Venegas, vecino en la collación de Santa María, y un tal Diego Pérez de León. AHPSPN, leg. 111, ff. 7-ss. 
cometido demandar todos los maravedíes, pan, trigo, cebada, aceite, gallinas y cualquier tipo de género que se debiera al dicho monasterio; recaudar las rentas de casas y tierras de pan, olivares o viñas; efectuar transacciones las bancarias que fueran necesarias; realizar y cobrar arrendamientos, pedir comisos o promover pleitos ${ }^{23}$.

Volviendo a su faceta artística, la colaboración de Chacón con otros artistas de la ciudad es prueba irrefutable de la posición que ocupó dentro del gremio y de la estima en que se tenía su buen quehacer artístico. En 1568, por ejemplo, firmó contrato junto al escultor Gaspar del Águila, conviniéndose ambos a ejecutar un Crucifijo de dos varas y una ochava para el convento de Nuestra Señora de Montesión. Se emplearía madera de pino de segura para la efigie y de borne para la cruz, habiéndose de dar terminado al pintor a fines de octubre, para que la policromase. El precio de la talla sería 30 ducados, a saldar en tres pagas, como solía ser habitual. Desconocemos cuánto se pagó a Chacón por sus labores pictóricas, pero lo cierto es que la obra había sido ya entregada el 31 de enero del año siguiente $^{24}$. También junto a él, en 1574, contrató la hechura de un retablo para la capilla de San Pedro de la iglesia mayor de Llerena, advocada a Nuestra Señora de la Granada ${ }^{25}$. Chacón se encargaría de trazar el retablo - diseño que quedó inmortalizado en un boceto a disposición del demandante- y de otorgar policromía a las esculturas, así como de realizar las tablas pictóricas que incluía el retablo ${ }^{26}$. Su vinculación a Gaspar del Águila fue exitosa, pues en el mismo año en que acometen dicho encargo, Chacón actuaría como fiador de aquel en una obra que contrató junto a Juan Bautista Vázquez para la ciudad de Écija. Se trataba de un encargo de los ilustres señores del concejo, quienes requirieron un San Pablo acompañado de cuatro angelitos, una parihuela y un tabernáculo ${ }^{27}$.

${ }^{23}$ AHPSPN, leg. 110, ff. 819-ss.

${ }^{24}$ Noticia dada por LÓPEZ MARTÍNEZ, Celestino: Desde Jerónimo Hernández a Martínez Montañés. Sevilla, 1929, p. 21.

${ }^{25}$ Se finiquitó el pago de los 400 ducados que costó el 16 de mayo de 1575 . Documento hallado y reseñado brevemente por LÓPEZ MARTÍNEZ, Celestino: "Artistas y gentes de mar sevillanas", El Correo de Andalucía, 12-12-1961. Recogido en CARRASCO GARCÍA, Antonio: Escultores, pintores y plateros del Bajo Renacimiento en Llerena. Badajoz, 1982, p. 18. Analizado y estudiado convenientemente por SANTOS, Antonio Joaquín: "Nueva aportación documental a la obra del escultor Gaspar del Águila", Temas de estética y arte, 22, 2008, pp. 121-136.

${ }^{26}$ La labor de diseñador no le era ajena pues, en 1573, participó como tracista del banco y sagrario que el entallador Juan de Oviedo se obligó a hacer para el convento de Santa Clara. Documento publicado por LÓPEZ MARTÍNEZ, Celestino: Desde Jerónimo..., op. cit., pp. 105-106.

${ }^{27}$ El documento, riquísimo desde el punto de vista histórico-artístico, no deja ningún detalle sin tratar. Se pagó por esta obra un total de 170 ducados, otorgando un tiempo de 
Asimismo, actuó como fiador del retablo que Gaspar del Águila se obligó a hacer para la iglesia de San Mateo, en la gaditana Jerez de la Frontera. Fue el arzobispo de Sevilla quien le encargó la obra en el año 1578, otorgándole un plazo de seis meses para darla concluida ${ }^{28}$. Por tanto, vemos que fue con aquel con quien estrechó más lazos, siendo su relación especialmente cercana en los últimos momentos de su vida.

Sus labores como policromador se extendieron en paralelo al trabajo con otros pintores. Junto a Antonio de Alfián, otorgó valores cromáticos al primitivo retablo mayor de la iglesia de la Magdalena, encargo conocido gracias a la escritura por la cual Jerónimo Hernández y Gaspar del Águila testifican en la obligación, junto con el también pintor de imaginería Blas López de Altopica, cuya vida y obra son aún desconocidas ${ }^{29}$. Por otro lado, a principios de los años setenta, su nombre aparece vinculado a la decoración de la Galera Real, proyecto dirigido por el entonces arquitecto del concejo, Benvenuto Tortello, napolitano de envidiable reputación en su oficio. Este resolvió como árbitro, en compañía de Alfter Agripina Colonnes, las diferencias que surgieron entre el capitán Antonio de Alzate y los pintores Juan Chacón, Antonio de Alfián y Luis Hernández, con motivo de los trabajos de ornamentación del navío. Finalmente, se convino a pagar 1.900 reales al escultor Juan Bautista Vázquez el Viejo por la obra realizada para la popa de esta galera, mientras que el pintor Pedro Bonilla recibió 8 ducados por dorar un escudo, y a Alfián y a Chacón se les retribuyó con 14 ducados el dorado y pintura de un San Rafael de tamaño natural ${ }^{30}$. Se desconoce qué otros trabajos pudo realizar en esta galera o si su participación queda reducida a dicho encargo. La ejecución del complejo programa iconográfico diseñado por el Bergamasco y modificado, para mayor honra de don Juan de Austria, por Juan de Mal-Lara, recayó sobre los principales artistas del momento, que se encargaron de materializar aquellas ideas humanistas y propagandísticas, así como de policromar y estofar las esculturas y relieves ${ }^{31}$.

Chacón fue reclamado por todos y cada uno de los sectores de la clientela local, pues gracias a un pago efectuado en 1577 sabemos que también trabajó para el concejo civil. Es entonces cuando acomete la realización de una gruta en el extremo norte del jardín del Crucero del Alcázar, por encargo del teniente alcaide

tres meses para la finalización de la misma. Documento publicado por LÓPEZ MARTÍNEZ, Celestino: Desde Jerónimo..., op. cit., pp. 105-106.

${ }^{28}$ Ibidem, p. 172.

${ }^{29}$ Ibid., p. 243.

${ }^{30}$ Ibid., p. 15.

${ }^{31}$ Para conocer más acerca de la Galera Real de Lepanto y la participación de diferentes artistas sevillanos en su ornamentación, ver CAMARERO, Emma: La Galera Real de Lepanto. La Sevilla mitológica y pagana y el arte de la decoración naval: https://issuu. com/proyectonica/docs/la_galera_real_de_lepanto (Consultado el 28-10-2016). 
Juan Antonio del Alcázar ${ }^{32}$. El pintor comenzó a trabajar en ella el 5 de agosto de ese año, concluyéndola a comienzos del mes de abril siguiente. Fue una grutafuente valorada en un total de 210 ducados y, según se desprende de la documentación, debió ser ornamentada con múltiples figuras de barro cocido, pintadas de muy diversos colores ${ }^{33}$. Sería además decorada con la plasmación de un Olimpo, iconografía que complementaría aquella otra realizada en el jardín del Crucero por el pintor Gonzalo Pérez, donde se representaron las insignias de los distintos meses del año, según dicta la documentación conservada, la cual no especifica el modo de representación, si alegóricamente o simbolizado por atributos ${ }^{34}$.

Los documentos encontrados presentan a un Juan Chacón inmerso en tareas de traza, pintura e incluso escultura. Fue hombre acomodado y bien posicionado socialmente, contándose entre su círculo cercano artistas de renombre y entre su clientela, la flor y nata más granada del panorama hispalense. Aparte de encargos directos, también trabajó para el mercado libre, surtiendo a comerciantes de obras que pudieran ser demandadas en otras localidades o al otro lado del mar océano. Así, en 1584, Antonio de Aranda, mercader tratante en imaginería, le compró seis Ecce Homos, de medio relieve, por precio de 24 ducados ${ }^{35}$. Siendo una iconografía muy demandada y propia del gusto contemporáneo, el artista debió crear un modelo, un tipo exitoso de escultura pequeña y devocional, que tendría muy buena acogida entre los compradores. Este hecho evidencia el doble sistema de producción que coexistió dentro de los obradores sevillanos: uno minucioso, y de gran calidad técnica, destinado a satisfacer encargos puntuales, y otro más mediocre, con ciertas notas de seriación, cuyo destino preferente era el mercado colonial y cuyo objetivo consistía en cubrir los pedidos realizados por mercaderes $^{36}$.

A pesar de que no se ha encontrado ningún documento de sus dotes o arras, las noticias de sus últimos años de vida llevan a considerar que debió contraer matrimonio por partida doble, pues a mediados de siglo, figuraba junto a Elvira Rodríguez, mientras que, en un testimonio de 1592, era Leonor Verdugo quien

${ }^{32}$ LÓPEZ MARTÍNEZ, Celestino: Desde Jerónimo..., op. cit., pp. 105-106.

${ }^{33}$ En la actualidad se conservan sus restos muy degradados. MARÍN FIDALGO, Ana: "Los jardines del Alcázar de Sevilla durante los siglos XVI y XVII. Intervenciones y ordenación del conjunto en el quinientos", Cuadernos de La Alhambra, 24, 1988, pp. 127-128.

${ }^{34}$ La hipótesis de una decoración olímpica fue sugerida por LLEÓ CAÑAL, Vicente: Nueva Roma. Mitología y humanismo en el Renacimiento sevillano. Sevilla, 1979, p. 90.

${ }^{35}$ Noticia dada por LÓPEZ MARTÍNEZ, Celestino: Desde Martínez Montañés hasta Pedro Roldán. Sevilla, 1932, p. 178, aunque obvia las condiciones del contrato.

${ }^{36}$ SÁNCHEZ, José María: "Los obradores artísticos sevillanos del siglo XVI: adaptaciones y cambios para satisfacer los encargos del mercado americano", Anales del Instituto de Investigaciones Estéticas, 103, 2003, p. 183. 
aparece como su esposa ${ }^{37}$. Dada su extensa trayectoria vital no es de extrañar que enviudara y casara con esta en segundas nupcias. El nombre de la segunda es conocido gracias al hallazgo de un encargo interesante y muy sorprendente, en la medida en que la pareja es "convenida de dorar y pintar" el retablo que Diego López de Ábalos y su mujer, Teresa Coronado, encargaron para el altar mayor de la iglesia de Omnium Sanctorun de Sevilla ${ }^{38}$. La obra es contratada por ambos, asumiendo así su esposa responsabilidades en la tarea a realizar. Leonor Verdugo no se cita como pintora, ni siquiera como doradora, pero los términos en los que se hace la escritura los involucran a ambos, por lo que se puede pensar que su segunda mujer no solo fue su esposa sino también una colaboradora activa dentro de su taller, al menos para llevar a cabo tareas menores. El matrimonio recibió las piezas y los relieves en su obrador, por lo que su cometido se limitó al dorado y policromado de una obra ya ejecutada por un maestro entallador cuya identidad se desvela. La lectura detenida de las condiciones permite cerciorarse de su habilidad para dicha labor, dado el rigor y minuciosidad exigidos (Apéndice documental). Sin embargo, es un documento donde la iconografía se olvida en pos de los tecnicismos propios de las labores pictóricas, por lo que desconocemos las escenas presentes en los diferentes cuerpos y calles del retablo. Tendrían 16 meses para entregarlo concluido, recibiendo por ello 800 ducados, una cantidad importante que permite intuir la magnitud del retablo y la calidad pretendida en la ejecución. En el caso de faltar a su palabra, incumpliendo así el referido contrato, la pareja se comprometía a dar seis casas extramuros de la ciudad, que poseían en la collación de San Roque, concretamente en la calzada que iba a la Cruz del Campo, y que el propio Juan Chacón había levantado en un par de solares que fueron propiedad del convento de San Benito. Esta cláusula, tan inesperada como original, supone un dato más para el análisis de las capacidades económicas del pintor, el cual atesoraba en importante número de propiedades tanto fuera como dentro de los lindes urbanos.

El último documento firmado, con trazo tembloroso, por Juan Chacón data de 1593. Se trata del recibo de un pago correspondiente a una obra que realizó en el monasterio de Santa Justa y Santa Rufina, extramuros de la ciudad de Sevilla, según encargo del mayordomo Miguel Romero ${ }^{39}$. Además, el contenido del documento permite conocer otro trabajo del artista para la iglesia del convento, que

${ }^{37}$ Únicamente he podido documentarlo otorgando carta de dote a su sobrina, Leonor Díaz Chacón, hija de su hermano Antonio de Mora y su mujer, María Díaz, ambos difuntos. Casó con Hernán González, quedando la dote concertada en 62.000 maravedíes, de los cuales 24.000 se otorgaría en bienes muebles y ajuar. El resto sería dado en dineros. AHPSPN, leg. 177, ff. 201-ss.

${ }_{38}$ AHPSPN, leg. 188, ff. 799-ss., y en hoja aparte las condiciones.

${ }^{39}$ Noticia publicada por HERNÁNDEZ DÍAZ, José: Arte Hispalense de los siglos $X \mathrm{~V}$ y XVI, en Documentos para la Historia del Arte en Andalucía. T. IX. Sevilla, 1937, p. 57. 
lo descubre en una nueva faceta, nunca antes revelada. Juan Chacón fue también pintor de ventanas. A pesar de ser un arte y oficio en extinción, pues el ocaso del vidrio coloreado llegó a Europa a finales del siglo XVI, tanto por motivos internos -innovaciones técnicas y nuevos materiales-, como externos -el cambio de gusto, la Reforma, la iconoclastia, el conflicto religioso, la negligencia-, en España vivió un espléndido desarrollo durante esta centuria ${ }^{40}$. Encargos como este evidencian que las vidrieras seguían en uso y valoración, pues no solamente eran una prolongación de los programas iconográficos preconcebidos para los edificios religiosos, sino que eran elementos con los que la arquitectura se identificaba, determinando el sentido de la idea espacial y, a través del cual, la religiosidad de la época se veía reflejada y expresada por la arquitectura ${ }^{41}$.

A la espera de encontrar el testamento de Juan Chacón, esta es la última noticia que ha quedado de su vida y obra, por lo que su trayectoria vital se inserta en los tres últimos cuartos del siglo XVI, como ocurriera con el también pintor Pedro Villegas Marmolejo. Resulta desalentador conocer tantas referencias documentales huérfanas de obras materiales, cuya conservación ayudaría a estudiar su arte y valorar su talento. Corrió su fama la misma suerte que la de otros contemporáneos suyos, quienes, olvidados por las pérdidas de la historia, renacen entre el polvo de los protocolarios legajos. Fue Chacón un pintor de celebridad y fortuna, un artista versátil y bien posicionado dentro gremio, siempre cerca de un cabildo catedralicio a la vanguardia, de unos comitentes acaudalados y de unos artistas cuya maestría debió ser fuente de aliento e inspiración para él.

\section{APÉNDICE DOCUMENTAL}

Archivo Histórico Provincial de Sevilla, sección Protocolos Notariales, leg. 188, ff. 799-ss., y en hoja aparte las condiciones.

"Sepan quantos esta carta vieren como yo, Juna Chacon, pintor de ymagineria e yo Leonor Verdugo, su mujer, vecinos de la collación de San Marcos, yo la dicha Leonor Verdugo con liçencia e plaçer e consentimiento del dicho mi marido que esta presente, qual yo le pido e demando e el me da, otorgamos e juramos lo que en esta escritura sea contenido [fórmulas notariales] de mancomun otorgamos e conocemos al señor Diego Lopez de Avalos, vecino en la collacion de Santa Maria, que esta ausente e decimos que por quanto el quiere facer un retablo para el altar de la capilla mayor de la iglesia de Omnium Sanctorum de esta cibdad e para el dorar e pintar e adereçar el dicho retablo, estan fecha unas condiçiones

40 BROWN, Sarah y O'CONNOR, David: Vidrieros. Madrid, 2009, p. 10. Para conocer más acerca de las vidrieras durante el siglo XVI, ver NIETO ALCAIDE, Víctor: La vidriera en el Renacimiento en España. Madrid, 1970.

${ }^{41}$ NIETO ALCAIDE, Víctor: Arnao de Vergara. Sevilla, 1994, pp. 33-34. 
con lo suso dicho que se ha de facer e nosotros habemos visto e leido las quales damos y entregamos al presente escribano para que las ponga e incorpore en esta escritura su tenor de ellas quales son estas que se siguen.

Aquí las condiciones.

Por tanto nos los dichos Juan Chacon y Leonor Verdugo, su mujer, debaxo de la dicha mancomunidad que tenemos fecha somos convenidos e conçertados con el dicho Diego Lopez de Avalos de tomar e por la presente tomamos a nuestro cargo e nos obligamos de hacer la dicha obra con todo lo en ella contenida e de la tener fecha e acabada en toda perfeçion sin haber en ella falta ni defeto ni cosa en contra de las dichas condiciones dentro de 16 meses primeros siguientes que corren e se quentan desde luego, continuando sin alçar mano e entregandosenos la pieça e pieças del dicho retablo para que nosotros hagamos la dicha obra de pintura e dorado e lo demas que somos obligados a hacer conforme a las condiciones e habemos de aver y el dicho Diego Lopez de Avalos nos ha de dar e pagar a nosotros trescientos mil maravedíes en cuyo prometimiento tomamos a hacer e hacemos e acabaremos toda la dicha obra [cláusulas notariales].

Obligamos nuestras personas e bienes de cada uno de nos avidos e por aver y especialmente e señaladamente obligamos e ypotecamos por especial y expresa obligacion e ypoteca que cedemos seis casas juntas unas con otras que nosotros habemos e tenems fuera y cerca de esta cibdad de Sevilla en la collación de San Roque a la calzada de la cruz que lindan de una parte con casas de los herederos de Francisco de Aguirre e de la otra parte con casas de los herederos de Francisco Luis e por delante la calle e campo las quales dichas seis casas yo he dicho Juan Chacon yo hice e edifique e labre de nuevo en dos solares que tome del monasterio e convento de San Benito de Silos de esta cibdad de Sevilla por cierto precio de maravedíes de tributo que les pago en cada año y en tal manera, hacemos e otorgamos esta ypoteca de las dichas seis casas que nosotros ni algunos de nosotros podamos vender ni enagenar ni disponer de ellas en manera alguna hasta que hayamos fecho e cumplido e entregado la dicha obra sin que ninguna cosa de ello falte de cumplir e hasta que hayamos pagado e satisfecho todo lo que por esta escritura e por los dichos capitulos e condiciones somos obligados y si de otra manera vendieramos e enagenaremos las dichas casas o dispusieremos de ellas que todo sera en si ninguno e non valga como si no hubiese pasado [cláusulas notariales].

Fecha la carta en Sevilla a 18 julio 1592.

[Firman los escribanos y Juan Chacón]

[En hoja aparte]

Yten estas son las condiciones con las que se a de pintar e dorar e dereçar el retablo del altar mayor de la yglesia de Omnium Sanctorum de esta cibdad de Sevilla, los señores Diego Lopez y doña Teresa de Coronado, su mujer, mandan facer por servicio de Dios, a las quales se ha de obligar el pintor que de el se ha de encargar. 
Primeramente todo el retablo se a de aparejar muy bueno y [roto] asi de gruesos yesos y mates y en bolando todo lo que ha de ser dorado [roto] muy bien emplastecido y lo que fuere necesario enervado y en [roto] fechas las diligencias que para algunos nudos o resinas descubriere dedolo todo muy liso y bien acondicionado conforme a buena obra.

Yten es condiçion que a de ser todo cubierto de oro fino muy bien reganado e bruñido salvo las encarnaciones y el hueco de la cruz y algunos claros en mejoria de la obra con que las sillas han de ser doradas todas.

En lo que toca a la arquitectura, ha de ser dorado muy bien reseñado salvo los espacios de campos e plaças que si fuere neçesario se esgrafiaran para que [roto].

Yten las figuras e historias han de ser muy finas y fermosas colores con asules e carmesíes y carmesies finos de Indias y de lo mas que convenga en lo que fuere medio relieve a se ser aiudado de punta de pincel bien esgrafiado e de muy buenas labores de romanos y arabascos haziendo en algunas figuras algunas diferencias de labores de punta de pincel asi como en faxas, guarniciones todo de alegre y honesta obra y no se ha de facer mascarones ni grutescos ni otras cosas semejantes.

Yten todas las encarnaciones han de ser fechas de pulimentos en que sean muy pequeñas faciendo sus diferencias y toda esta obra ser tan bien colorida que la levante y no se confunda las figuras a las otras.

Yten es condición que las figuras de todo el retablo han de ser todas doradas [roto] en todo lo que se pudiere ver y la vista alcançe porque en lo que no puede ser visto solo se ha de empañar de alguna color que cubra la madera en especial en los juntos de todo relieve porque en si conviene considerando que todo a de ser como se acostumbra a façer e façe en los retablos.

Yten es condiçion que en las ystorias del banco y en las demas cosas menudas como son rostros e arboles e animales que van en las ystorias han de ir aparejados con muy delgados aparejos que no tapen nada de lo que fuere labrado de madera ni se añada ni quite cosa alguna de lo que estuviere labrado salvo en los estofados de las historias se han de enriquecer de varias y diversas colores sin tapar el relieve como esta dicho.

Yten la arquitectura del retablo ha de aver faxas de oro crespo en las partes que convenga y en los esgrafiados sea obligado a contrafacer brocados de diferentes colores que salga muy bien las figuras de las otras todo de muy finos colores y todas las figuras han de ir estofadas a punta de pinzel façiendo en las ropas labores muy galanas de cogollos e serafines tarjetas y niños, todo muy bien colorido de mano de muy buenos estofadores que salga toda la obra con mucha puliçia e limpieça.

Yten es condiçion que si para la bondad de esta obra aquí faltare alguna cosa por decir a de ser obligado el tal oficial que de esta obra se encargara a lo facer como si aquí fuere dicho y espresado, por que todo quede con mucha perfeçion acabado. 
Yten es condicion que ha de dar fiança al contento del señor Diego Lopez de Avalos y que luego que se faga la escritura se han de dar mil reales y dada la obra, mil reales, se le han de dar otros mil reales y por esta orden se le ha de dar todo el dinero hasta acabar la obra y ha de dar dorado al dicho retablo dentro de 16 meses desde el dia que se otorgo la escritura con que se le entrego el retablo y figuras conjuntamente para poder de ello acabar de dorar porque si no lo entregare a tiempo para poder de ello acabar y por su culpa y descuido no lo fiçiere dentro del dicho tiempo, que por cada mes que faltare le pague en pena de su descuido a Diego Lopez 50 ducados por los cuales le pueda ejecutar con solo su juramento e quien su poder oviere

Yten el precio que ha de aver por todo lo suso dicho son 300.000 maravedies, que valen 800 ducados con los quales se obliga de dar acabado de dorar y pintar y estofar y acabar de todo punto el dicho retablo a vista de oficiales puestos por el señor Diego Lopez de Arevalos y el dicho pintor, cada cual el suyo y en discordia ponga la justicia otro de oficio.

Yten es condiçion que el oficial que esta obra tomare no pueda pedir demasias de obra ni pueda alegar engaño ni mitad de justo precio ni lesion inorme ni inormisima antes siendo sabidor del justo precio como oficial de experiencia declara que el justo precio son las 300 mil mrv sobre dichos y dice que su voluntad de que si alguna demasia fiziere de obra oro e labores la tal demasia la dona i remite i da al dicho Diego Lopez de Arevalos por la aiuda del dicho retablo por ser como es la dicha obra [roto] y en servicio de nuestro señor y prometa de no la pedir y si la pidiere que no le valga.

Ytren es condiçion que si al asentar el dicho retablo se desdorare o demoliere o dehiciere alguna cosa que de fuerça sea y ha de hacer para que en todo punto quede acabado sin ningun defecto que en tal cargo ha de ser obligado a lo facer sin otro precio alguno mas del sobre dicho".

[Firmado por Juan Chacón]

Fecha de recepción: 9 de octubre de 2018

Fecha de aceptación: 11 de febrero de 2019 


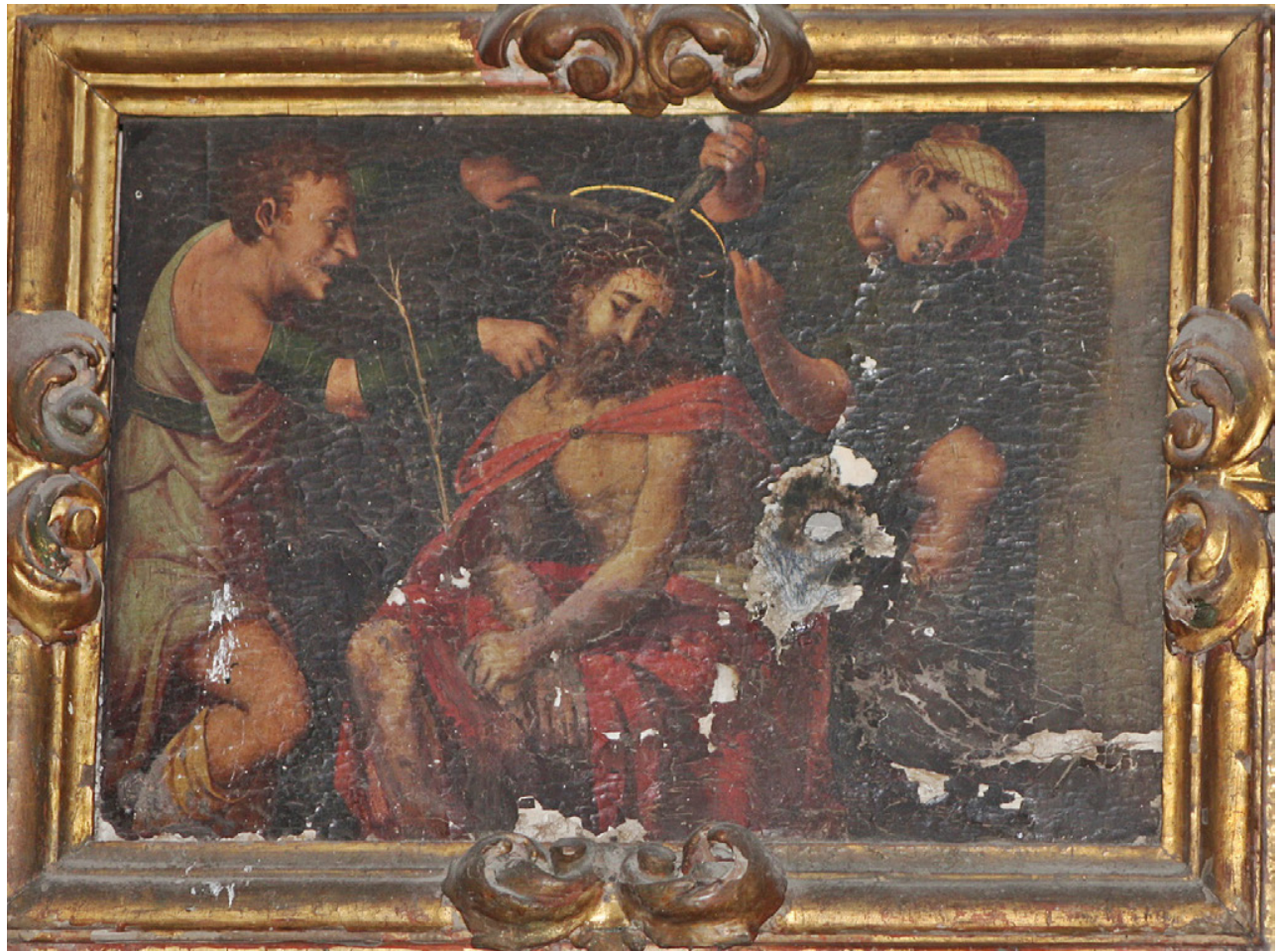

Figura 1. Juan Chacón, Coronación de espinas, 1553, iglesia del hospital de San Lázaro, Sevilla. Foto: Elena Escuredo Barrado. 


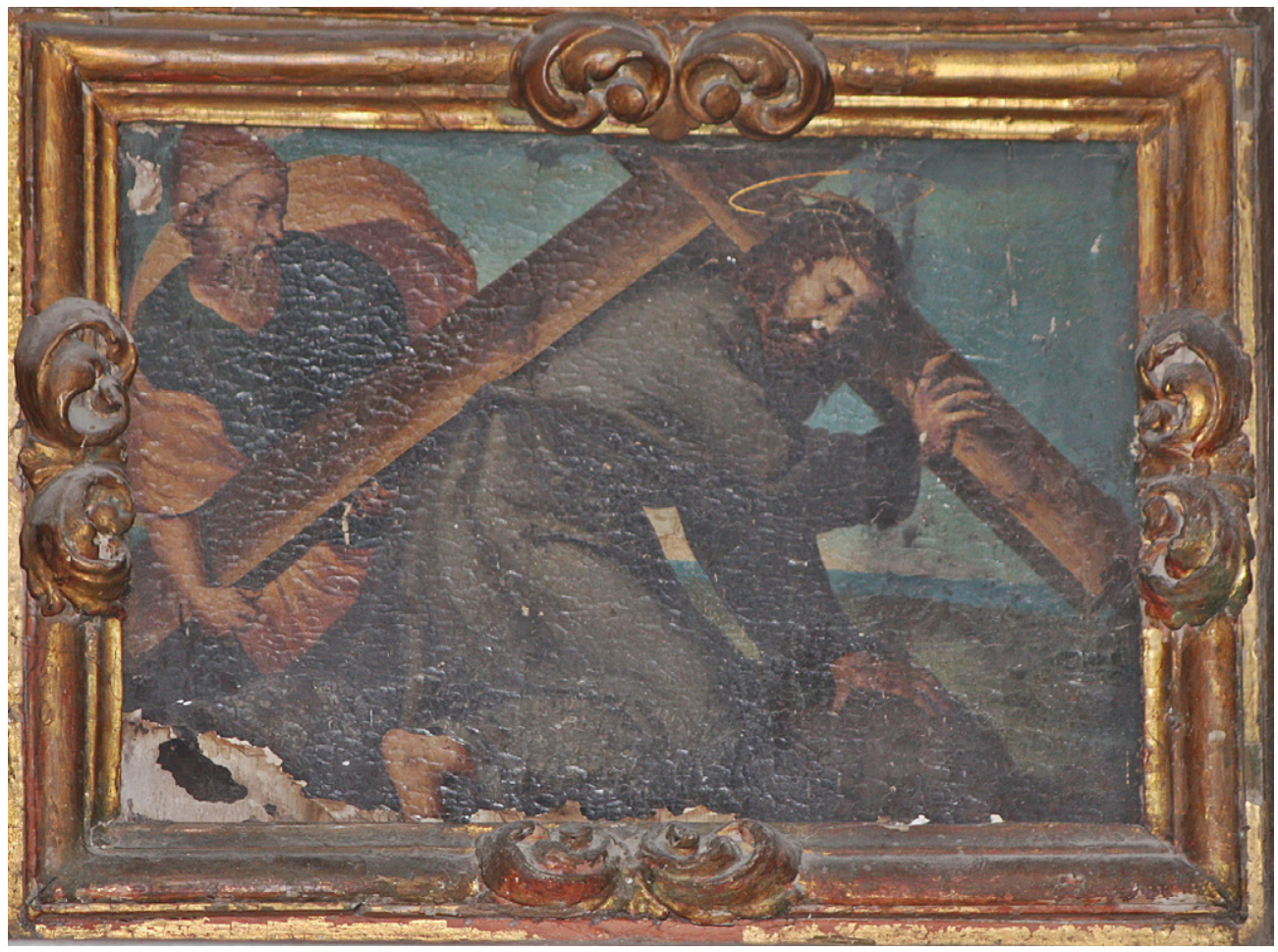

Figura 2. Juan Chacón, Cristo llevando la cruz, 1553, iglesia del hospital de San Lázaro, Sevilla. Foto: Elena Escuredo Barrado. 


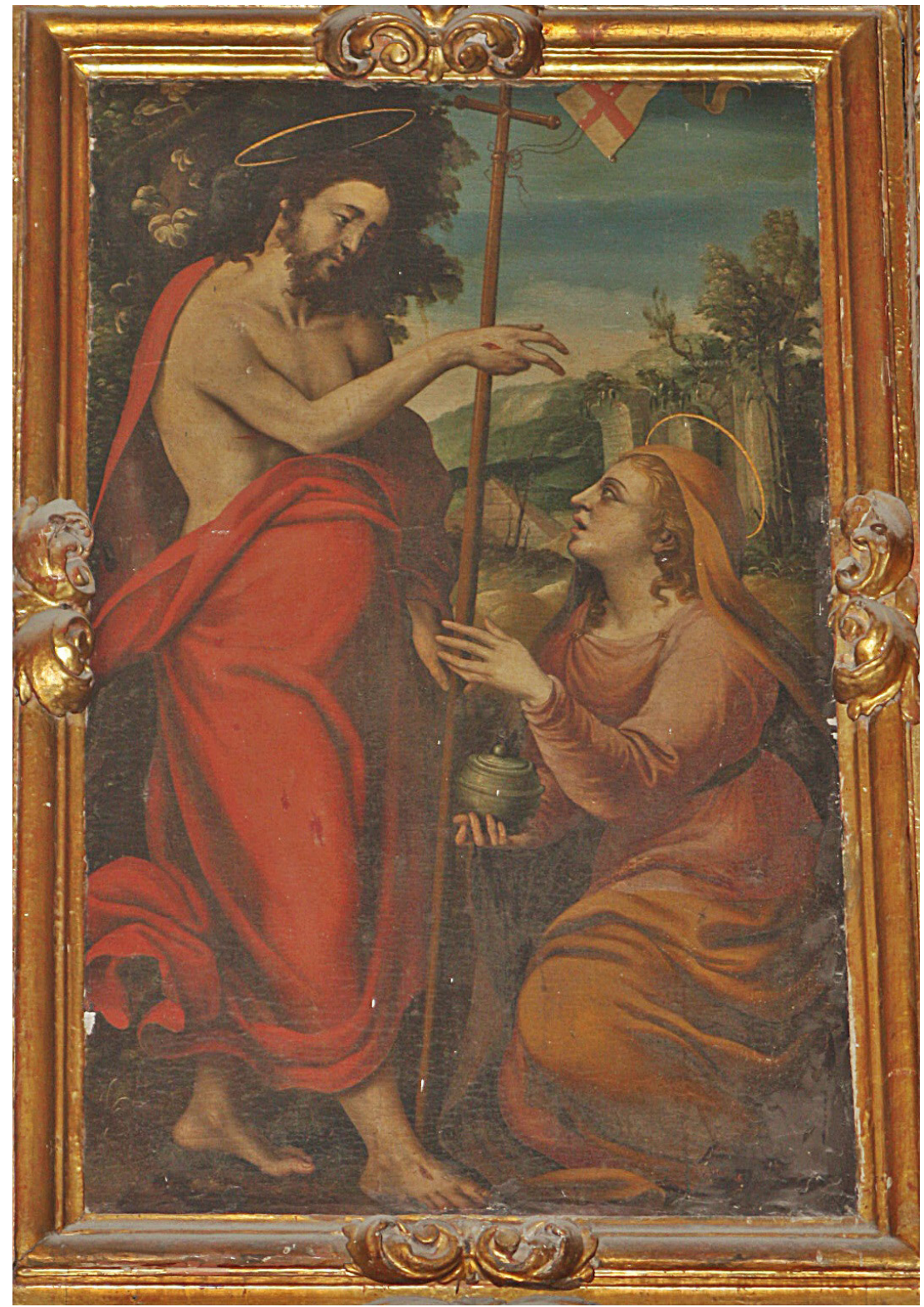

Figura 3. Pedro Villegas y Juan Chacón, Aparición de Cristo a la Magdalena, 1553, iglesia del hospital de San Lázaro, Sevilla. Foto: Elena Escuredo Barrado. 